\title{
Soil Carbon Storage Potential of the Home Gardens Adjoining Selected Natural Forests of the Southern Sri Lanka
}

\author{
Wijekoon W.M.C.J. ${ }^{1 *}$, Wanniarachchi S.D. ${ }^{1}$ and Samarawickrama U.I. ${ }^{2}$ \\ ${ }^{I}$ Department of Soil Science, Faculty of Agriculture, University of Ruhuna, Sri Lanka \\ ${ }^{2}$ Computer Unit, Faculty of Agriculture, University of Ruhuna, Sri Lanka \\ *wijekoon@soil.ruh.ac.lk
}

\begin{abstract}
Conversion of forests to other land uses is inevitable despite the environmental issues associated with forest clearing. Tropical home gardens have long been identified as a land-use system analogous to forests from various perspectives. Carbon storage in the tropical forest soils is estimated to be nearly $32 \%$ of the global soil carbon. Although few in number, research conducted in Sri Lanka has shown that the home garden soils could store relatively a large amount of carbon. Present study was conducted in the low country wet zone of Sri Lanka (WL2) using the topsoil $(0-15 \mathrm{~cm})$ and subsoil $(15-30 \mathrm{~cm})$ samples taken from two sets of home gardens (HG) adjoining two natural forests (Mulatiyana and Wilpita) where latter was used as benchmark sites. Twelve samples each was collected from the topsoil and the subsoil under each system reaching a total of 96 samples for the four systems. The objective was to assess the potential of the home garden soils to sequester carbon as an alternative to the dwindling carbon storage in forest soils. Analysis of bulk density data of 12 samples each from the HGs and forests showed no significant difference (T-test, $\alpha=0.05$ ) between the forests and the HGs for the selected soil depths. Therefore, the assessment of the systems was done in terms of the percentages of soil organic matter (SOM). All the comparisons were done using T test with $\alpha=0.05$. For the topsoil, Mulatiyana HGs and the forest had mean SOM contents of $4.14 \% \pm 0.98 \mathrm{SD}$ and $5.50 \% \pm 0.71 \mathrm{SD}$, respectively and, it was significantly different $(\mathrm{p}=0.001)$. On the contrary, Wilpita HGs and the forest had values 3.71\% $\pm 1.6 \mathrm{SD}$ and $3.17 \% \pm 0.059 \mathrm{SD}$, respectively and, they were not significantly different $(\mathrm{p}=0.296)$. When the two forests and the home gardens were compared separately, Mulatiyana forest had significantly higher SOM content $(\mathrm{p}=0.000)$ over Wilpita forest while the home gardens had no significant difference $(\mathrm{p}=0.437)$. When the subsoil was compared neither Mulatiyana forest and the HGs (3.62\% $\pm 0.64 \mathrm{SD}, 3.18 \% \pm 0.70 \mathrm{SD} ; \mathrm{p}=0.072)$ nor Wilpita forest and the HGs $(2.60 \% \pm 1.01 \mathrm{SD}$, $3.10 \% \pm 1.14 \mathrm{SD} ; \mathrm{p}=0.268$ ) had significant differences in the SOM contents. When the two forests and home gardens were compared separately, Mulatiyana forest had significantly higher SOM compared to Wilpita forest $(\mathrm{p}=0.008)$ while HGs had no significant difference $(\mathrm{p}=0.985)$. These results indicate that the soils of the home gardens adjoining the forests are capable of storing carbon almost up to the natural storage limit for a given locality. Hence, it can be envisioned that the carefully structured home gardens in view of capturing and storage of carbon could be a good alternative for the dwindling forests in the humid tropical environments.
\end{abstract}

Keywords: Soil carbon, Home gardens, Low country, Wet zone

Proceedings of the International Forestry and Environment Symposium 2016, Department of Forestry and Environmental Science, University of Sri Jayewardenepura, Sri Lanka. 